\title{
Study of correlation between polymorphism of ST6GALNAC2 and susceptibility to IgA nephropathy
}

\author{
CHEN LU ${ }^{1 *}$, WEN-LAN LI ${ }^{1 *}$ and YI-RAN MA ${ }^{2}$ \\ ${ }^{1}$ Nephrology and ${ }^{2}$ Medical Departments, People's Hospital of Xinjiang Uyghur Autonomous Region, \\ Urumqi, Xinjiang 830000, P.R. China
}

Received April 8, 2014; Accepted November 17, 2014

DOI: $10.3892 /$ etm.2015.2404

\begin{abstract}
The aim of the present study was to explore the correlation between single nucleotide polymorphisms (SNPs) rs3840858 and rs2304921 in a specific $\alpha-2,6$ sialyltransferase gene, ST6GALNAC2, and the susceptibility to immunoglobulin ( $\operatorname{Ig} \mathrm{A})$ nephropathy $(\operatorname{IgAN})$. The distributions of genotypes of SNPs rs3840858 and rs2304921 in ST6GALNAC2 were detected by direct sequencing. The distributions of the genotype and allele frequencies of rs3840858 in patients with IgAN were significantly different from those in the control group (genotypes, $\mathrm{P}=0.001$; alleles, $\mathrm{P}=0.001)$. The DI genotype ratio $(17.8 \%)$ in the $\operatorname{IgAN}$ group was higher than that in the control group (5.6\%) and the I allele frequency $(8.9 \%)$ in the $\operatorname{IgAN}$ group was higher than that in the control group (2.8\%). Univariate logistic regression analysis indicated that $\mathrm{rs} 3840858$ polymorphism is a risk factor of $\operatorname{IgAN}(\mathrm{P}=0.001)$. The risk of developing IgAN in individuals who carried the DI genotype was 3-fold higher than that in individuals who carried the DD genotype [odds ratio $(\mathrm{OR})=3.676,95 \%$ confidence interval $(\mathrm{CI})=1.284$ 10.519], and the risk of developing IgAN in individuals who carried the I allele was higher than that in individuals who carried the $\mathrm{D}$ allele $(\mathrm{OR}=3.415,95 \% \mathrm{CI}=1.223-9.531)$. The distributions of the genotype (AA, AG and GG) and allele (A and G) frequencies of rs2304921 did not have a statistically significant difference between patients with $\operatorname{IgAN}$ and those without $(\mathrm{P}>0.05)$. The SNP rs3840858 in the ST6GALNAC2 gene may be associated with the risk of developing $\operatorname{IgAN}$ in the population studied; however, polymorphism of rs2304921 appears to be irrelevant to the risk of developing IgAN in this population.
\end{abstract}

Correspondence to: $\mathrm{Dr}$ Chen Lu, Nephrology Department, People's Hospital of Xinjiang Uyghur Autonomous Region, 91 Tianchi Road, Urumqi, Xinjiang 830000, P.R. China

E-mail: luchenfml@163.com

*Contributed equally

Key words: Uyghur, IgA nephropathy, ST6GALNAC2 gene, gene polymorphism

\section{Introduction}

Immunoglobulin A ( $\operatorname{Ig} A)$ nephropathy $(\operatorname{IgAN})$, as one of the most common primary glomerular diseases, accounts for $30 \%-40 \%$ of primary glomerular diseases, the incidence of which is increasing year by year (1-3). Relevant followup studies have shown that for 25-30\% patients, IgAN will develop into end-stage renal disease after 20-25 years (4), which is the primary cause of maintenance hemodialysis in China at present (5). The clinical manifestations, pathological patterns and prognoses of IgAN show diversity, and the pathogenesis is not yet clear. Currently, it is considered that the pathogenesis is associated with infection, inflammation, immunological reactions and genetic factors (6,7). According to previous studies, the prevalence rate of $\operatorname{IgAN}$ shows certain geographical and ethnic differences, and genetic factors play a very important role in the onset of $\operatorname{Ig} \mathrm{AN}$ (8). Therefore, it is particularly important to search for genes associated with susceptibility to $\mathrm{IgAN}$ in order to provide a genetic target for therapeutic intervention in $\operatorname{IgAN}$. There have been many Chinese studies on candidate genes associated with the severity and complications of $\operatorname{IgAN}(9-11)$, whereas there have been few studies looking into the candidate genes associated with its pathogenesis. A large-sample study on IgAN carried out by Li et al in China revealed that variation of the ST6GALNAC2 gene is associated with genetic susceptibility to IgAN (12). The present study analyzed the correlation of polymorphism of a specific $\alpha-2,6$ sialyltransferase gene (ST6GALNAC2) and the susceptibility of the Uyghur population to $\operatorname{IgAN}$, so as to get a better understanding of the pathogenesis and genetic background of $\operatorname{IgAN}$ in the Uyghur region.

\section{Subjects and methods}

Subjects of study. A total of 180 cases of hospital patients and outpatients of Uyghur ethnicity (86 males and 94 females, average age, $38.81 \pm 11.06$ years), diagnosed with $\mathrm{Ig} \mathrm{AN}$ by renal biopsy in the Nephrology Department of the People's Hospital of Xinjiang Uyghur Autonomous Region (Urumqi, China) were collected. Renal biopsy pathological diagnostic criteria established by Zou in 2011 (13) were used as diagnostic criteria for $\operatorname{IgAN}$. Patients with secondary IgA deposition diseases, such as systemic lupus erythematosus (SLE), allergic 
Table I. Primers for rs3840858 and rs2304921.

\begin{tabular}{lll}
\hline Locus & \multicolumn{1}{c}{ Forward primer (5'-3') } & \multicolumn{1}{c}{ Reverse primer (5'-3') } \\
\hline rs3840858 & GCTGACAGCCTTAGCTCCCCCACGA & CACTCCTGCCACTGCGCTCTCTCCA \\
rs2304921 & AAAGCTTCCAAGGGGTAGGT & TCATCCTTCTCTGCTGTTGG \\
\hline
\end{tabular}

purpura, chronic liver diseases, ankylosing spondylitic renal damage and psoriatic renal damage were excluded. All the selected patients were unrelated, with permanent Uyghur residency, of three different generations and all lived in Xinjiang. The healthy controls were 180 healthy individuals (84 males and 96 females, average age, $37.53 \pm 11.68$ years) who went to the aforementioned hospital for medical examination from July 2008 to January 2013.

All subjects provided informed consent and participated voluntarily. This study was approved by the Medical Ethics Committee of The People's Hospital of Xinjiang Uygur Autonomous Region.

Reagents. The reagents used included the whole blood genomic DNA extraction kit (Shanghai Sangon Co., Ltd., Shanghai, China), Taq polymerase, $10 \mathrm{X}$ buffer, dNTP (including $\mathrm{MgCl}_{2}$ ), $\mathrm{ddH}_{2} \mathrm{O}$ (Beijing Dingguo Biotechnology Co., Ltd., Beijing, China) and DNA marker (BBI, SeraCare Life Sciences, Inc., Milford, MA, USA). The other reagents were conventional molecular biology reagents.

Design and synthesis of primers. The primer sequences (shown in Table I) of ST6GALNAC2 gene rs3840858 and rs2304921 were as previously described (12) and were verified using primer5 software (Premier Biosoft, Palo Alto, CA, USA). The primers were synthesized by Shanghai Sangon Co., Ltd., following the requirements of the project group.

\section{Research methods}

Collection of blood samples. A $5 \mathrm{ml}$ sample of venous blood was collected from each patient on an empty stomach in the morning. EDTA was used for anticoagulation. The samples were numbered and registered. Whole blood samples were placed at $-80^{\circ} \mathrm{C}$ for cryopreservation.

DNA extraction. DNA specimens were extracted with the Ezup pillar blood genomic DNA extraction kit according to the kit instructions and preserved at $-20^{\circ} \mathrm{C}$.

Detection of gene polymorphism. i) PCR reaction conditions for SNP rs2304921. The total volume of the amplification

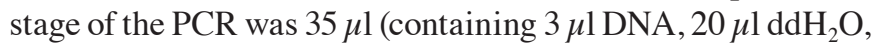
$5 \mu \mathrm{l}$ buffer, $2 \mu \mathrm{l} \mathrm{dNTP}$, and 1.2 and $2 \mu \mathrm{l}$ Taq polymerase in the upstream and downstream directions, respectively). The amplification reaction conditions of PCR were: denaturation at $95^{\circ} \mathrm{C}$ for $5 \mathrm{~min}$; main cycling at $95^{\circ} \mathrm{C}$ for $45 \mathrm{sec}, 61.7^{\circ} \mathrm{C}$ for $60 \mathrm{sec}$ and $72^{\circ} \mathrm{C}$ for $45 \mathrm{sec}, 38$ cycles in total; followed by $72^{\circ} \mathrm{C}$ for $10 \mathrm{~min}$ and preservation at $4^{\circ} \mathrm{C}$. The $\mathrm{PCR}$ reaction was performed on the GeneAmp ${ }^{\circledR}$ PCR System 9700 Thermal cycler from Applied Biosystems ${ }^{\circledR}$, Invitrogen Life Technologies (Foster City, CA, USA).

ii) PCR reaction conditions for SNP rs3840858. The total volume of the amplification reaction of PCR was $35 \mu 1$
Table II. Gender and age distribution in the IgAN and control groups.

\begin{tabular}{lcccc}
\hline Item & $\begin{array}{c}\text { IgAN } \\
\text { group }\end{array}$ & $\begin{array}{c}\text { Control } \\
\text { group }\end{array}$ & $\begin{array}{c}\text { t- or } \\
\chi^{2} \text { value }\end{array}$ & P-value \\
\hline Age (years) & $38.81 \pm 11.06$ & $37.53 \pm 11.68$ & 0.754 & 0.452 \\
Gender (M/F) & $86 / 94$ & $84 / 96$ & 0.045 & 0.833
\end{tabular}

IgAN, immunoglobulin A nephropathy; M, male; F, female.

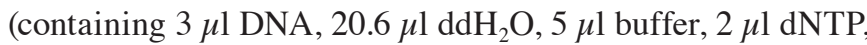
1.5 and $2 \mu 1$ Taq polymerase in the upstream and downstream directions, respectively). The amplification reaction conditions of PCR were: denaturation at $95^{\circ} \mathrm{C}$ for $5 \mathrm{~min}$; main cycling conditions at $95^{\circ} \mathrm{C}$ for $45 \mathrm{sec}, 61.0^{\circ} \mathrm{C}$ for $60 \mathrm{sec}$ and $72^{\circ} \mathrm{C}$ for $45 \mathrm{sec}, 37$ cycles in total; followed by $72^{\circ} \mathrm{C}$ for $10 \mathrm{~min}$ and preservation at $4^{\circ} \mathrm{C}$.

iii) Genotyping. Every PCR amplification product was electrophoresed at a voltage of $120 \mathrm{~V}$ for $20 \mathrm{~min}$ using $1.5 \%$ agarose gel to which ethidium bromide nucleic acid dye had been added in advance. Imaging was conducted using a UV transmission automatic image analyzer (Bio-Rad Laboratories, Inc., Hercules, CA, USA). All PCR products for each SNP locus were genotyped by direct sequencing (conducted by Beijing Dingguo Biotechnology Co., Ltd.).

Statistical analysis. Whether the genotypes of the population were in Hardy-Weinberg equilibrium was estimated using the $\chi^{2}$ test. Other statistical analyses were performed with SPSS software, version 17.0 (SPSS, Inc., Chicago, IL, USA). The allele and genotype frequencies were calculated by $\chi^{2}$ test. A t-test was applied for comparison of measurement data between groups. Logistic regression analysis was applied to analyze the correlation between polymorphism and $\operatorname{IgAN}$. All statistics are two-sided with a test level $\mathrm{a}=0.05$. $\mathrm{P}<0.05$ was considered to indicate that a difference was statistically significant.

\section{Results}

General patient characteristics. There was no statistically significant difference in terms of gender and age between the IgAN group and the control group ( $\mathrm{P}>0.05$; Table II).

Distributions of genotype and allele frequencies of rs 3840858 in the ST6GALNAC2 gene. Two genotypes, a DD genotype and a DI genotype, were detected by direct forward sequencing (Fig. 1), and the II genotype was absent. The distributions of 
Table III. Distribution of genotype and allele frequencies of rs3840858 polymorphism of the ST6GALNAC2 gene in the IgAN and control groups.

\begin{tabular}{|c|c|c|c|c|c|}
\hline \multirow[b]{2}{*}{ Group } & \multirow[b]{2}{*}{ No. of cases } & \multicolumn{2}{|c|}{ Genotype frequency, n (\%) } & \multicolumn{2}{|c|}{ Allele frequency, $\mathrm{n}(\%)$} \\
\hline & & DD & DI & $\mathrm{D}$ & I \\
\hline IgAN & 180 & $148(82.2)$ & $32(17.8)$ & $328(91.1)$ & $32(8.9)$ \\
\hline Control & 180 & $170(94.4)$ & $10(5.6)$ & $350(97.2)$ & $10(2.8)$ \\
\hline$\chi^{2}$-value & & 13.046 & & 12.238 & \\
\hline $\mathrm{P}$-value & & 0.001 & & 0.001 & \\
\hline
\end{tabular}

IgAN, immunoglobulin A nephropathy.

Table IV. Correlation between polymorphism of the ST6GALNAC2 gene and the susceptibility to IgAN.

\begin{tabular}{|c|c|c|c|c|c|}
\hline Genotype or allele & Control group, n (\%) & IgAN group, $\mathrm{n}(\%)$ & P-value & OR & $95 \% \mathrm{CI}$ \\
\hline \multicolumn{6}{|l|}{ rs3840858 } \\
\hline \multicolumn{6}{|l|}{ Genotype } \\
\hline DD & $170(94.4)$ & $148(82.2)$ & & 1 & \\
\hline DI & $10(5.6)$ & $32(17.8)$ & 0.001 & 3.676 & $1.284-10.519$ \\
\hline \multicolumn{6}{|l|}{ Allele } \\
\hline $\mathrm{D}$ & $350(97.2)$ & $328(91.1)$ & & 1 & \\
\hline I & $10(2.8)$ & $32(8.9)$ & 0.001 & 3.415 & $1.223-9.531$ \\
\hline \multicolumn{6}{|l|}{ rs 23840858} \\
\hline \multicolumn{6}{|l|}{ Genotype } \\
\hline AA & $6(3.3)$ & $4(2.2)$ & & 1 & \\
\hline GG & $54(30.0)$ & $72(40.0)$ & 0.778 & 1.3 & $0.209-8.082$ \\
\hline $\mathrm{AG}$ & $120(66.7)$ & $104(57.8)$ & 0.176 & 0.65 & $0.349-1.211$ \\
\hline \multicolumn{6}{|l|}{ Allele } \\
\hline G & 294 (81.7) & $280(77.8)$ & & 1 & \\
\hline A & 66 (19.3) & $80(22.2)$ & 0.228 & 1.273 & $0.760-2.132$ \\
\hline
\end{tabular}

IgAN, immunoglobulin A nephropathy., OR, odds ratio; CI, confidence interval.

the DD and DI genotypes in the IgAN and control groups were in accordance with Hardy-Weinberg equilibrium $(\mathrm{P}>0.05)$. As shown in Table III, the DI genotype ratio (17.8\%) in the IgAN group was higher than that in the control group $(5.6 \%)$, while the DD genotype ratio (82.2\%) in the IgAN group was lower than that in the control group (94.4\%). A statistically significant difference was observed in the distributions of each genotype between the $\operatorname{IgAN}$ and control groups $\left(\chi^{2}=13.046\right.$, $\mathrm{P}=0.001)$.

In the $\operatorname{Ig} \mathrm{AN}$ group, the I allele frequency (8.9\%) was higher than that in the control group (2.8\%), while the D allele frequency $(91.1 \%)$ was lower than that in control group (97.2\%). There was a statistically significant difference in the I and D allele distributions between the IgAN group and the control group $\left(\chi^{2}=12.238, \mathrm{P}=0.001\right)$.

Univariate logistic regression analysis indicated that rs3840858 polymorphism may be a risk factor of $\operatorname{IgAN}$
$(\mathrm{P}=0.001)$. The risk of developing $\operatorname{IgAN}$ in individuals who carried the DI genotype was 3-fold higher than that in those who carried the DD genotype [odds ratio $(\mathrm{OR})=3.676$, $95 \%$ confidence interval $(\mathrm{CI})=1.284-10.519]$, and the risk of developing $\operatorname{Ig} \mathrm{AN}$ in individuals who carried the I allele was higher than that in those who carried D allele $(\mathrm{OR}=3.415$, 95\% CI=1.223-9.531; Table IV).

Distributions of genotype and allele frequencies of rs2304921 in the ST6GALNAC2 gene. Three genotypes, GG, AG and AA genotypes, were detected by direct reverse sequencing (Fig. 2). The distributions of the GG, AG and AA genotypes in the $\operatorname{Ig} \mathrm{AN}$ and control groups were in accordance with Hardy-Weinberg equilibrium ( $\mathrm{P}>0.05)$. As demonstrated in Table IV, the AG genotype rate $(40.0 \%)$ in the IgAN group was higher than that in control group $(30.0 \%)$, while the AA and GG genotype rates $(2.2 \%$ and 
Table V. Distribution of genotype and allele frequencies of rs2304921 polymorphism of the ST6GALNAC2 gene in the IgAN and control groups.

\begin{tabular}{|c|c|c|c|c|c|c|}
\hline \multirow[b]{2}{*}{ Group } & \multirow[b]{2}{*}{ No. of cases } & \multicolumn{3}{|c|}{ Genotype frequency, n (\%) } & \multicolumn{2}{|c|}{ Allele frequency, $\mathrm{n}(\%)$} \\
\hline & & GG & AG & AA & G & A \\
\hline IgAN & 180 & $104(57.8)$ & $72(40.0)$ & $4(2.2)$ & $280(77.8)$ & $80(22.2)$ \\
\hline Control & 180 & $120(66.7)$ & $54(30.0)$ & $6(3.3)$ & $294(81.7)$ & $66(19.3)$ \\
\hline$\chi^{2}$-value & & & 4.114 & & 1.684 & \\
\hline P-value & & & 0.128 & & 0.228 & \\
\hline
\end{tabular}

IgAN, immunoglobulin A nephropathy.

$C G G G C C C G G C A C T C G G C C I C T A G A C I C I G T G G C G G G$

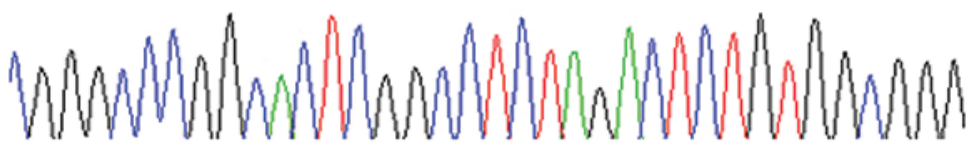

(1) DD genotype, homozygous deletion

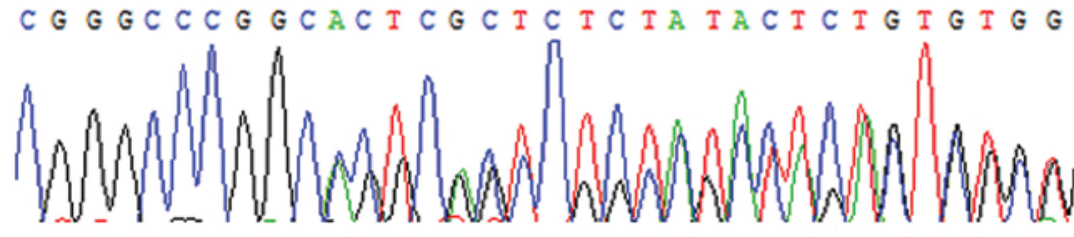

(2) DI genotype, heterozygote

Figure 1. Genotypes of rs3840858 polymorphism in the ST6GALNAC2 gene.

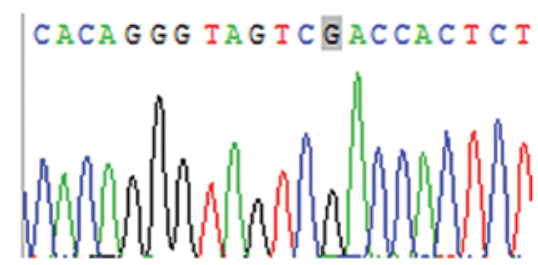

(1) GG genotype, wild type
CACAGGG TAG I T G A A C T T

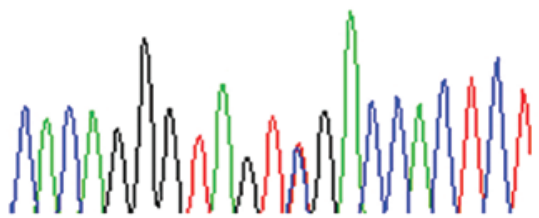

(2) AG genotype, heterozygote

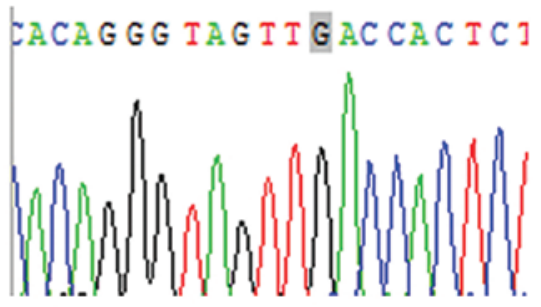

(3) AA genotype, mutant

Figure 2. Genotypes of rs2304921 polymorphism in the ST6GALNAC2 gene.

$57.8 \%$, respectively) in the IgAN group were lower than those in the control group (3.3\% and $66.7 \%$, respectively). The differences in the distributions of each genotype of the ST6GALNAC2 gene rs2304921 polymorphism between the IgAN and control groups were not statistically significant $\left(\chi^{2}=4.114, \mathrm{P}=0.128\right)$.
The A allele frequency (22.2\%) in the IgAN group was higher than that in the control group (19.3\%), while the $\mathrm{G}$ allele frequency $(77.8 \%)$ in the $\operatorname{IgAN}$ group was lower than that in the control group (81.7\%). The difference in A and $\mathrm{G}$ allele distributions between the $\operatorname{Ig} \mathrm{AN}$ group and the control group was not statistically significant $\left(\chi^{2}=1.684, \mathrm{P}=0.228\right)$. 
Univariate logistic regression analysis demonstrated that the rs2304921 polymorphism is not likely to impact the risk of developing $\operatorname{IgAN}(\mathrm{P}>0.05$; Table $\mathrm{V})$.

\section{Discussion}

The serum IgA levels of the majority of patients with IgAN increase (14). However, due to lack of specificity, this cannot be regarded as a criterion for assisting clinical diagnosis. In recent years, with several kinds of technologies such as ELISA and mass spectrometry, scholars from research institutions in Japan, the United States of America and China all observed that aberrant glycosylation of IgA1 molecules in IgAN patients may be the most important mechanism of pathogenesis (15-17). It has been widely accepted that glycosylation defects lead to the formation of immune complexes in the pathogenesis of $\operatorname{IgAN}$. The study conducted by Gharavi et al (18) suggests that glycosylation defects of IgA1 are a genetic characteristic and a genetic risk factor of IgAN. Thus, aberrant glycosylation provided a new candidate gene for the study of the genetic susceptibility of IgAN.

The ST6GLNAC2 gene encodes a specific $\alpha-2,6$ sialyltransferase enzyme that participates in galactosylation in the $\operatorname{IgA}$ formation process. The study conducted by Patsos et al (19) indicates that defective expression of the ST6GLNAC2 gene decreases the activity of $\alpha-2,6$ sialyltransferase. According to the literature, $\alpha-2,6$ sialyltransferase activity on serum IgA1 in patients with focal proliferative type and sclerotic type IgAN (Haas stage III-IV) is reduced, which delays the sialylation of GalNAc in the molecular hinge area of serum IgA1 and affects the galactosylation of O-linked glycosyl in this area, eventually causing changes to the molecular charge and spatial structure of IgA1 (20). An increase in the activity of $\alpha-2,6$ sialyltransferase may cause premature sialylation of GalNAc in the molecular hinge area of serum IgA1 and then affect the galactosylation of O-linked glycosyl in this area (21).

Li et al (12) conducted a large-sample study with sporadic Han IgAN patients as subjects. The results demonstrated that the frequency of the ADG haplotype in the promoter region of the ST6GALNAC2 gene was increased in patients with IgAN, and the ADG haplotype was associated with a deficiency of $\alpha-2,6$ sialylation of IgA1. The authors also analyzed the correlation between variants of C1GALT1 and ST6GALNAC2 genes and the predisposition and severity of IgAN. The results revealed that the IgA1 O-glycosylation-related genes, C1GALT1 and ST6GALNAC2, were associated with the disease predisposition and severity of IgAN.

The analysis of SNP rs3840858 in the ST6GALNAC2 gene in this study revealed the existence of two genotypes (DD and DI) as detected by sequencing; the DI genotype rate in the IgAN group was higher than that in the control group, and the I allele frequency in the IgAN group was higher than that in the control group. The differences between the two groups were significant. Moreover, univariate logistic regression analysis showed that the risk of developing IgAN in individuals who carried the DI genotype was 3 -fold higher than that in those who carried DD genotype. This suggests that the rs 3840858 polymorphism is associated with the susceptibility to IgAN. In the study by Li et al (12), three genotypes (DD, DI and II) of SNP rs3840858 were detected by a restriction enzyme digestion technique and the differences in the genotype and allele frequencies between IgAN and control groups was not found to be statistically significant. The lack of conformity of the results may be due to geographic and ethnic differences in the gene polymorphism.

The analysis of SNP rs2304921 in the ST6GALNAC2 gene in this study revealed the existence of three genotypes (GG, AG and AA) as detected by sequencing. The differences in genotype and allele frequencies between the IgAN group and control group were not statistically significant, which suggests that the rs2304921 polymorphism is irrelevant to the susceptibility to IgAN. This result was in accordance with the study by Li et al (12).

To conclude, this study indicated that the rs 3840858 polymorphism of the ST6GALNAC2 gene might be associated with the susceptibility to IgAN in an Uyghur population, whereas rs2304921 polymorphism appears to be irrelevant to IgAN in Uyghur. Due to the limited sample size, the correlation of the ST6GALNAC2 gene with susceptibility to IgAN requires investigation in a multi-zone and multi-site study with a larger sample size so as to provide new evidence for risk prediction as well as prevention and treatment.

\section{Acknowledgements}

This study was supported by the Natural Science Foundation of Xinjiang Uyghur Autonomous Region (Grant number: 2012211A088) and Science and Technology Support Xinjiang Autonomous Region Project (Grant number: 2013911114).

\section{References}

1. Zhang YQ: Pathological and clinical analysis of $\operatorname{IgA}$ nephropathy. Zhong Guo Xian Dai Yi Yao Za Zhi 17: 72, 2010 (In Chinese).

2. Yang DS, Luo CG, Jiang WM, et al: Observation of efficacy of combination therapy with Leflunomide and hormone on IgA nephropathy. Zhong Guo Xian Dai Yi Yao Za Zhi 17: 74-75, 2010 (In Chinese)

3. Li LS and Liu ZH: Epidemiologic data of renal diseases from a single unit in China: analysis based on 13,519 renal biopsies. Kidney Int 66: 920-923, 2004.

4. Barratt J and Feehally J: IgA nephropathy. J Am Soc Nephrol 16: 2088-2097, 2005.

5. Chen XM and Xie YS: Attach importance to basic and clinical research on the postponement of progression of IgA nephropathy. Chin J Nephrol 20: 235-237, 2004 (In Chinese).

6. Yu XQ, Li M, Zhang H, Low HQ, Wei X, Wang JQ, Sun LD, Sim KS, Li Y, et al: A genome-wide association study in Han Chinese identifies multiple susceptibility loci for $\operatorname{IgA}$ nephropathy. Nat Genet 44: 178-182, 2011.

7. Yu HH, Chu KH, Yang YH, et al: Genetics and immunopathogenesis of IgA nephropathy. Clin Rev Allergy Immunol 41: 198-213, 2011.

8. Kiryluk K, Julian BA, Wyatt RT, et al: Genetic studies of IgA nephropathy: past, present, and future. Pediatr Nephrol 25: 2257-2268, 2010.

9. Wang H, Sui W, Xue W, Wu J, Chen J and Dai Y: Univariate and multiple linear regression analyses for 23 single nucleotide polymorphisms in 14 genes predisposing to chronic glomerular diseases and IgA nephropathy in Han Chinese. Saudi J Kidney Dis Transpl 25: 992-997, 2014.

10. Xu R, Feng S, Li Z, Fu Y, et al: Polymorphism of DEFA hinese Han population with IgA nephropathy. Hum Genet 133: 1299-1309, 2014

11. Mao S, Ren X, Huang S and Zhang A: Association of megsin 2093C/T, 2180C/T and C25663G gene polymorphism with the risk of IgA nephropathy. Ren Fail 36: 817-822, 2014. 
12. Li GS, Zhu L, Zhang H, et al: Variants of the ST6GALNAC2 promoter influence transcriptional activity and contribute to genetic susceptibility to IgA nephropathy. Hum Mutat 28: 950-957, 2007

13. Zou WZ: Guidance on renal biopsy pathologic diagnostic criteria. Chin J Nephrol 17: 270-275, 2001 (In Chinese).

14. Zhu B, Zhu CF, Lin Y, Perkovic V, et al: Clinical characteristics of $\operatorname{Ig} \mathrm{A}$ nephropathy associated with low complement 4 levels. Ren Fail: 1-9, Dec 24, 2014 (Epub ahead of print).

15. Shimozato S, Hiki Y, Odani H, Takahashi K, Yamamoto K and Sugiyama S: Serum under-galactosylated $\operatorname{IgA} 1$ is increased in Japanese patients with IgA nephropathy. Nephrol Dial Transplant 23: 1931-1939, 2008.

16. Gharavi AG, Moldoveanu Z, Wyatt RJ, Barker CV, Woodford $\mathrm{SY}$, et al: Aberrant IgA1 glycosylation is inherited in familial and sporadic IgA nephropathy. J Am Soc Nephrol 19: 10081014, 2008.
17. Lin XJ, Ding JX, Zhu L, et al: Aberrant galactosylation of IgA1 is involved in the genetic susceptibility of Chinese patients with Ig A nephropathy. Nephrol Dial Transplant 24: 3372-3375, 2009.

18. Gharavi AG, Moldoveanu Z, Wyatt RJ, et al: Aberrant IgAl glycosylation is inherited in familial and sporadic IgA nephropathy. J Am Soc Nephrol 19: 1008-1014, 2008.

19. Patsos G, Hebbe-Viton V, Robbe-Masselot C, et al: O-glycan inhibitors generate aryl-glycans, induce apoptosis and lead to growth inhibition in colorectal cancer cell lines. Glycobiology 19: 382-398, 2009.

20. Ding JX, Xu LX, Lv JC, et al: Aberrant sialylation of serum IgA1 was associated with prognosis of patients with IgA nephropathy. Clin Immunol 125: 268-274, 2007.

21. Zhu L, Ding JX, Lv JC, et al: Expression of ST6GALNAC2 gene in B lymphocytes is influenced in Epstein-Barr virus transformation. Chinese Journal of Nephrology 24: 130-133, 2008 (In Chinese). 